\title{
Weak swimming response of a bdelloid rotifer to chemical cues of a native copepod predator
}

\author{
Marta Parysek $^{1} \cdot$ Barbara Pietrzak $^{1}$ (D)
}

Received: 11 March 2020 / Accepted: 1 September 2020 / Published online: 11 September 2020

(c) The Author(s) 2020

\begin{abstract}
Whether bdelloid rotifers can detect and respond to the chemical cues of predators has not been studied, and research on their behaviour is scarce in general. To test for such response, we observed the behaviour of Philodina megalotrocha rotifers in either control or copepod-conditioned water. We then introduced a mechanical disturbance to test if predator odour sensitises rotifers to subsequent cues. We found intensified swimming in P. megalotrocha exposed to Macrocyclops fuscus-conditioned water, i.e. the larger and more predatory of the tested copepods. Such response may be adaptive, depending on the predominant hunting mode of the predator in the particular habitat.
\end{abstract}

Keywords Anti-predatory response $\cdot$ Behaviour $\cdot$ Mechanical cue $\cdot$ Chemical cue $\cdot$ Kairomone $\cdot$ Bdelloid rotifer

\section{Introduction}

Prey discriminate predators and different types of risk entailed, yet, as they live in complex environments, they rarely receive cues independently of one another. Chemical cues of predator presence are often the first detected. They may provide a context in which the animals respond to subsequent ambiguous cues and make them more alert (Parsons et al. 2018). Guppies exposed first to chemical alarm cue are more responsive to later ambiguous visual cues (Stephenson 2016). Water fleas escape more effectively, if they were earlier exposed to predator kairomone (Pietrzak et al. 2017). Such a reinforcement is seen in different taxa and may be common in aquatic animals.

Bdelloid rotifers are a behaviourally understudied group of microscopic animals. This physiologically and morphologically homogenous group is famous for at least two extraordinary features: era-long history of obligate parthenogenesis (Welch and Meselson 2000) and exceptional

Electronic supplementary material The online version of this article (https://doi.org/10.1007/s10164-020-00676-w) contains supplementary material, which is available to authorized users.

Barbara Pietrzak

b.pietrzak@uw.edu.pl

1 Department of Hydrobiology, Institute of Functional Biology and Ecology, Faculty of Biology, Biological and Chemical Research Centre, University of Warsaw, Warsaw, Poland capabilities of anhydrobiosis (Ricci 1987; Kaczmarek et al. 2019). Indeed, asexuality and dormancy can be considered the key traits of the evolutionary and ecological success of bdelloids (Ricci 1987, 2017; Wilson and Sherman 2013). Leaving sympatric enemies behind, a single dormant individual is able to colonise any suitable habitat in which it lands (Wilson and Sherman 2013). In addition, bdelloid degree of habitat specialisation is generally low and their ecological tolerance is wide (Fontaneto et al. 2011), all followed by wide geographic distributions (Fontaneto et al. 2008). Spatiotemporal decoupling from coevolving enemies (Wilson and Sherman 2013) may thus be considered the primary long-term defence strategy in the group. Strong selection on predator species-specific behavioural responses would then not be expected. Yet at the same time, like myriads of other small aquatic animals, in their active form they are vulnerable to a wide range of predators and physical challenges, requiring efficient behavioural defence mechanisms.

Recognition of chemical cues of predation is ubiquitous among aquatic prey. Bdelloid biology suggests possibly weakened selection on the evolution of responses to particular species of predators. We test the basic hypothesis that a bdelloid rotifer recognises chemical cues of sympatric predator and alters swimming behaviour accordingly. This shall manifest either as (1) a direct response to such stressor present individually or as (2) an enhanced response to a combination of stressors. 


\section{Materials and methods}

\section{Animal collection and culture}

Bdelloid rotifer Philodina megalotrocha Ehrenberg, 1832 (Fig. S1) and cyclopoid copepods Macrocyclops fuscus (Jurine, 1820) and Mesocyclops leuckarti (Claus, 1857) were used as the prey and the predators. Philodina megalotrocha (Philodinidae) is a cosmopolitan species (Jaturapruek et al. 2018) often found on aquatic vegetation in open water (Ricci 1987; Pejler and Bērziņš 1993). The rotifers used in this study were collected with common bladderwort (Utricularia vulgaris) from a small pond in the Botanical Garden-Centre for Biological Diversity and Conservation, Polish Academy of Sciences, in Powsin in summer 2017 and 2018. Copepods of both species were collected from the same pond, in consecutive years, respectively.

After collection, the animals were grown under laboratory conditions for weeks. The rotifers were cultured in a 11 glass container with conditioned lake water with the common bladderwort. Once a week, $1 \mathrm{ml}$ of concentrated Acutodesmus obliquus green algae culture was added. The copepods were grown individually on a 24-well test plate in $1.5 \mathrm{ml}$ of filtered lake water. Once a week, $0.01 \mathrm{ml}$ of A. obliquus was added. All animals were grown at a temperature of $21{ }^{\circ} \mathrm{C}$ (see also below) and in summer photoperiod (16L: 8D). Experiments with M. fuscus as predator (I) were performed in August 2017, experiments with $M$. leuckarti (II) in August 2018.

\section{Predation tests}

To confirm the anecdotal reports on the possible predation of M. fuscus and M. leuckarti on P. megalotrocha, predation tests were carried out. To this end, for each predator, eight $0.2 \mathrm{ml}$ cavity slides were used as predation arenas, five rotifers were placed in each cavity $(2 \times 8 \times 5=80$ individuals), and into half of them one predator was added. After $24 \mathrm{~h}$, the number of rotifers remaining on each slide was recorded.

\section{Predation response experiments}

In each experiment, for seven consecutive days, every day two adult $P$. megalotrocha were randomly picked from the culture and each was placed on a slide with $0.2 \mathrm{ml}$ of conditioned lake water either with or without chemical cue of predation. The slides were covered to minimise evaporation and the rotifers were thus incubated for $24 \mathrm{~h}$.
The water with copepod chemical cues was obtained by exposing a single adult copepod (M. fuscus in experiment I, M. leuckarti in experiment II), a different individual for each test, in $0.2 \mathrm{ml}$ of conditioned lake water for $24 \mathrm{~h}$ before the intended use.

After 24-h individual exposure in water with or without copepod chemical cues, the rotifers were filmed, each three times, all recordings under the same lighting conditions. Three drops of freshly obtained conditioned water with or without copepod cues were added to the appropriate slide (for chemical cue refreshment) and $15 \mathrm{~min}$ were allowed to stabilise the behaviour of the rotifer. The animals were filmed for five minutes. After the first four minutes, three gentle strokes to the glass of the slide were applied with a dissecting needle. The impacts simulated a direct threat to which the rotifer respond with change in behaviour (personal observation). Repeated recordings were carried out every $15 \mathrm{~min}$, alternating between control and copepod cueexposed rotifers.

Experiment II was replicated and performed also with rotifers cultured in $22{ }^{\circ} \mathrm{C}$. In total, the behaviour of 42 rotifers was filmed ( 3 experimental trials $\times 2$ treatments $\times 7$ individuals) in 126 recordings ( 3 repeated recordings).

\section{Behavioural states}

We distinguished six basic behavioural states (activities) in the over four hours of one-second-accuracy analysed recordings of the Philodina megalotrocha rotifers. Three behaviours were without displacement: (1) curling-pulling the foot telescopically into the trunk and pulling in the corona (trochi retracted into the head), (2) sensing-activity of the sensory organ, rostrum, while with foot attached to the substratum, and (3) wheeling-filter feeding: rotating activity of the ciliary corona, mastax moving steadily, while with foot attached. Three behaviours were types of movement: (4) circling - spinning, swimming in tiny circles, (5) swimming-directional movement through water, propelled by the rotating activity of the corona, and (6) crawling-creeping, directional movement on the substratum: attaching posterior end to the substratum, stretching forward, then attaching the anterior end and then releasing the foot and drawing the rear end forward.

\section{Data analysis}

The last two minutes of each recording, i.e. one minute before and one minute after the mechanical stimulus, were analysed using the blinded experiment method. All observations were assigned to one of the above described six distinct behavioural states. The start and end time of each activity was recorded with one-second accuracy. For each recording, the total time spent in each behavioural state and the 
time to uncurl after mechanical stimulus were calculated. The effects of predator cues treatment and experiment were tested and the events upon mechanical disturbance were analysed. As there were no significant differences in behavioural patterns between the two consecutive replicates of experiment II, their results were pooled. All calculations were performed using the $\mathrm{R}$ language and environment $(\mathrm{R}$ Core Team 2019).

Overall time spent in different behavioural states were extracted and the data were visualised using R-package TraMineR (Gabadinho et al. 2011). To allow for correlation of errors (repeated recordings for individual rotifers) and unequal variances, we fitted a linear model using generalised least squares (GLS) to the time of swimming data using nlme package (Pinheiro et al. 2019). Repeated measurements for individual rotifers were considered in the error structure of the model and type-II analysis-of-variance table was calculated for the model using Anova function of $\mathrm{car}$ package (Fox and Weisberg 2019). To test for differences in uncurling time, Cox proportional hazards regression model $(\mathrm{COXPH})$ was fitted to curling time data using treatment and experiment as covariates, using survival package (Therneau et al. 2020). Wald statistic $\mathrm{z}$ was used to evaluate, whether the coefficients of the variables tested were statistically significantly different from 0 . Holm-Bonferroni sequential correction was used to account for multiple testing.
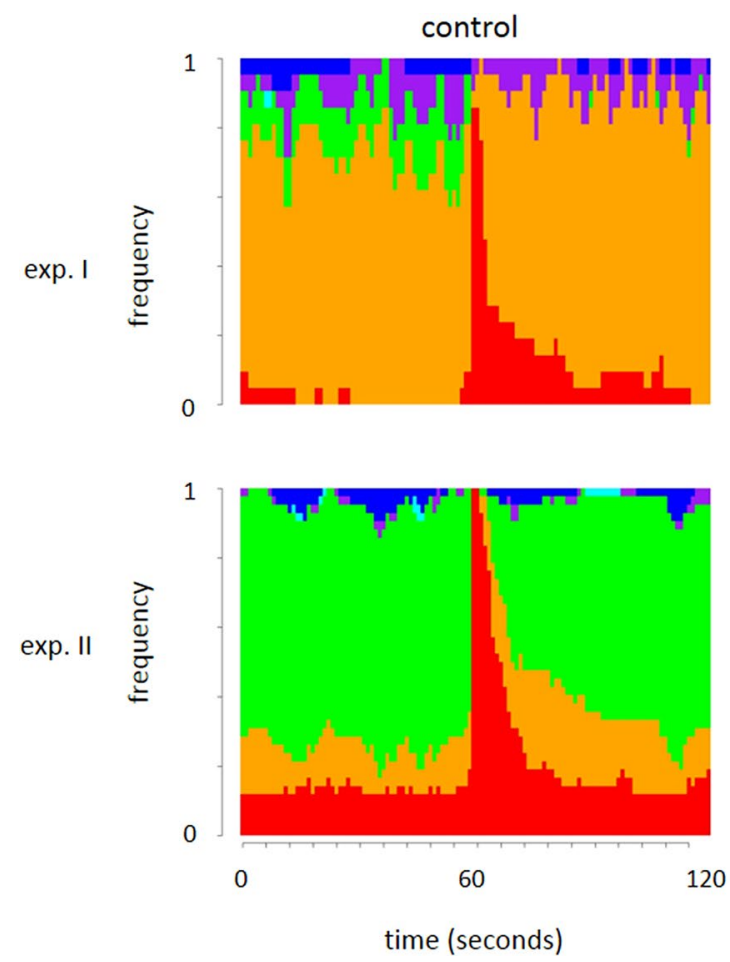

Fig. 1 Frequency of different Philodina megalotrocha behaviours at consecutive times during the experiments (exp I. $n=21$, exp. II $n=42$, per treatment). The total area of each panel represents $100 \%$

\section{Results}

24-h predation trials showed both tested cyclopids, Macrocyclops fuscus and Mesocyclops leuckartii, used Philodina megalotrocha as prey (median $0 \%$ rotifer survival in the presence of each predator versus median $100 \%$ survival in both controls).

The recorded rotifers spent most time stationarily, either exploring the surroundings by the means of rostrum movements (sensing; 70\% observations in experiment I) or feeding, i.e. beating the wheel organ (wheeling; $58 \%$ observations in experiment II) (Figs. 1, S2). Rotifers in $M$. fuscus-conditioned water spent more time swimming than did rotifers in control water: $6.1 \%(3.1-10 \%)$ versus $0 \%(0-3.8 \%)$, respectively (median (1st-3rd quartiles), ANOVA on GLS results: $\left.\chi 2_{1}=3.98, p=0.046\right) . M$. leuckarti-conditioned water had no effect on the swimming pattern.

The most prominent and invariable was the curling response to the mechanical stimulus applied at second 60 of the analysed samples (Fig. 1). Upon mechanical shock rotifers abruptly stopped other activities and curled in $95 \%$ of observations. Median time spent curling after shock was $6 \mathrm{~s}$, with no effect of experiment or treatment on uncurling time (Cox regression; experiment: $z=-0.91$,

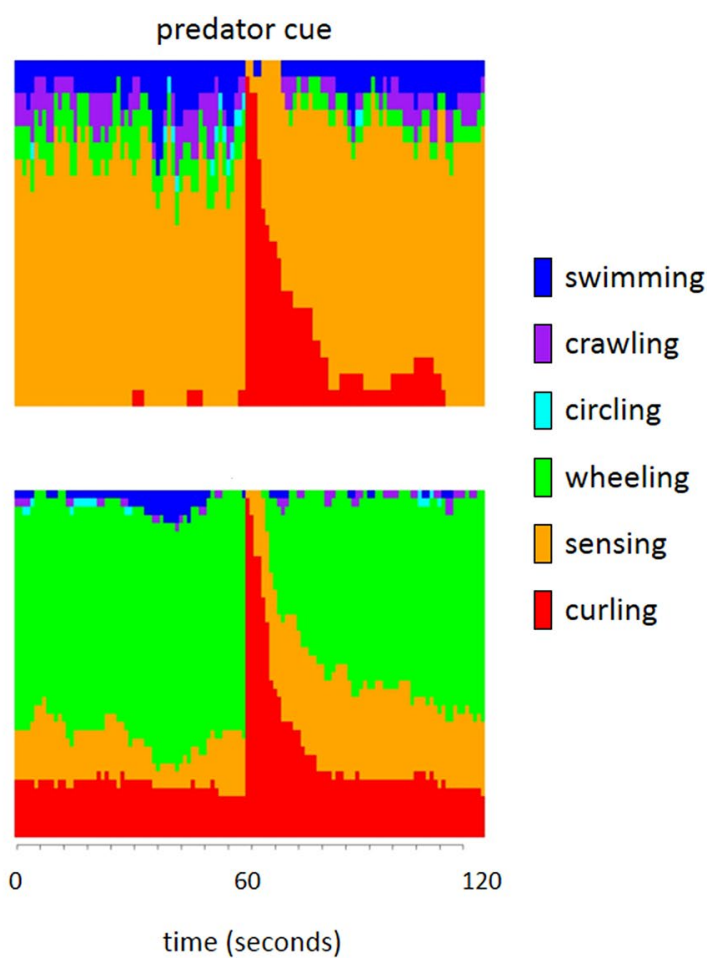

observations. Mechanical stimulus was introduced at second 60 of the analysed recordings 
$p=0.36$, treatment: $z=-0.82, p=0.42$ ). For the purpose of quantifying this response, the few "all-curling" rotifer recordings were excluded from analysis, as the response to stimulus could not be assessed there. This intervention did not introduce bias, as these recordings were distributed equally between predator and control treatments (5 out of 63 recordings in each treatment).

\section{Discussion}

Although our understanding of animal integration of multiple stimuli in producing behavioural responses is growing, experimental studies are incessantly needed. We addressed that gap by exposing small aquatic prey, bdelloid rotifers, to chemical cues of their sympatric predators and subsequent mechanical disturbance, testing for both, direct response to predator cue and increased alertness.

In the presence of chemical cues of one of the tested predators, Macrocyclops fuscus, P. megalotrocha swam more than in control water. To our knowledge, this is the first report of a bdelloid responding to chemical cues of predator presence. It is also one of the few to show behavioural alteration in response to chemical cues of predation in any rotifer (Gilbert 2014, 2018). The vast literature on rotifer phenotypic plasticity in response to predator presence includes the records of rotifers distinguishing kairomones of different threatening species (Gilbert 2009). Yet, it concerns almost exclusively monogont rotifers altering their morphology or life history (Gilbert 2013; Riessen and Gilbert 2019).

Predator odours elicit a plethora of behavioural responses in prey. Escape, altered swimming patterns or increased distances moved are among them, like in Littoraria snails moving faster in the presence of the mucus of molluscan predators (Dix and Hamilton 1993). Recently, increase in the overall activity was found in fruit flies in the presence of actively hunting predators, as opposed to decreased activity under the cues of ambush ones (Parigi et al. 2019). Our finding of more time spent swimming in the presence of cues of one of the predators stays in line with the findings of Parigi et al. (2019).

We also found recurrent curling reaction of Philodina megalotrocha upon sudden disturbance. This drawing-in of the appendages in response to mechanical shock was described before for bdelloids (the contraction of the body, Ricci and Melone 2000) and is likely a general response reducing risk of mechanical damage. In our study rotifers uncurled and resumed activity within seconds after shock, and chemical cues of predation had no effect on uncurling time nor on frequency of curling response. Thus, predator cues had here no effect on prey alertness. Yet, control animals curled uniformly, which left little space for reinforcement by pre-exposure to predation cues.
The generally weak effects of the particular predator cues may be due to weak cue recognition. Signal strength, the concentration of chemical cues, was likely high, as copepod densities by far smaller or similar to ours were previously successfully used to induce prey morphological or life history response (in alga: Lürling and van Donk 1997, in monogonont rotifers: García et al. 2007, Nandini et al. 2014). Weak (selection on) specific cue recognition could be attributed to short or loose joint evolutionary history and result from cosmopolitanism of the prey and its wide range of habitats and predators therein. This is coupled with life-history avoidance strategy through dormancy (Wilson and Sherman 2013). Dormancy together with high dispersal propensity of the dormant stages is a common defence strategy in aquatic invertebrates (García-Roger et al. 2019; Ślusarczyk et al. 2019).

P. megalotrocha in our study responded to cues of Macrocyclops fuscus but not to cues of Mesocyclops leuckarti. The response to only one of the two predators can be a result of actual recognition of only one of them. It can also be due to different environmental contexts in which the rotifers were tested, if only in one of these settings these cues elicit behavioural response. We controlled for the basic environmental parameters in the laboratory and kept them unchanged between experiments, still, the predominant foraging patterns of control rotifers differed between tests performed in two consecutive years. An uncontrolled factor diversified the results which allowed us to capture a broader spectrum of behavioural patterns, without a possibility for further inference, though.

More questions remain, including those regarding the chemical nature of the cue, important issue in the study of interspecific interactions (Pijanowska et al. 2020). The first question in this regard might be whether the rotifers react to copepodamides-copepod-exuded taurine conjugated lipids that have been shown to induce defence responses in dinoflagellates and diatoms (Grebner et al. 2019). We hope the study presented here will open a new line of research on rotifer behaviour.

Acknowledgements We thank D. Fontaneto and anonymous reviewer for insightful comments that helped improve the manuscript. We thank D. Fontaneto and J. Ejsmont-Karabin for help with rotifer species identification. The study was supported by 2016/23/D/NZ8/01736 National Science Centre grant to BP.

Author contributions MP and BP conceived the idea and designed the study. MP sampled and cultured the animals, performed the experiments, analysed the recordings and provided the first draft. BP provided the final analysis of the data and lead writing the manuscript.

\section{Compliance with ethical standards}

Conflict of interest The authors declare that they have no conflict of interest. 
Open Access This article is licensed under a Creative Commons Attribution 4.0 International License, which permits use, sharing, adaptation, distribution and reproduction in any medium or format, as long as you give appropriate credit to the original author(s) and the source, provide a link to the Creative Commons licence, and indicate if changes were made. The images or other third party material in this article are included in the article's Creative Commons licence, unless indicated otherwise in a credit line to the material. If material is not included in the article's Creative Commons licence and your intended use is not permitted by statutory regulation or exceeds the permitted use, you will need to obtain permission directly from the copyright holder. To view a copy of this licence, visit http://creativecommons.org/licenses/by/4.0/.

\section{References}

Dix TL, Hamilton PV (1993) Chemically mediated escape behavior in the marsh periwinkle Littoraria irrorata Say. J Exp Mar Biol Ecol 166:135-149

Fontaneto D, Barraclough TG, Chen K, Ricci C, Herniou EA (2008) Molecular evidence for broad-scale distributions in bdelloid rotifers: Everything is not everywhere but most things are very widespread. Mol Ecol 17:3136-3146

Fontaneto D, Westberg M, Hortal J (2011) Evidence of weak habitat specialisation in microscopic animals. PLoS ONE 6:e23969

Fox J, Weisberg S (2019) An R companion to applied regression, 3rd edn. Sage, Thousand Oaks CA. https://socialsciences.mcmaster. ca/jfox/Books/Companion/

Gabadinho A, Ritschard G, Müller NS, Studer M (2011) Analyzing and visualizing state sequences in $\mathrm{R}$ with TraMineR. J Stat Softw 40:1-37

García CE, De C-H, Nandini S, Sarma S (2007) Life-history strategies of Brachionus havanaensis subject to kairomones of vertebrate and invertebrate predators. Chem Ecol 23:303-313

García-Roger EM, Lubzens E, Fontaneto D, Serra M (2019) Facing adversity: dormant embryos in rotifers. Biol Bul 237:119-144

Gilbert JJ (2009) Predator-specific inducible defenses in the rotifer Keratella tropica. Freshw Biol 54:1933-1946

Gilbert JJ (2013) The cost of predator-induced morphological defense in rotifers: experimental studies and synthesis. J Plankton Res $35: 461-472$

Gilbert JJ (2014) Morphological and behavioral responses of a rotifer to the predator Asplanchna. J Plankton Res 36:1576-1584

Gilbert JJ (2018) Attachment behavior in the rotifer Brachionus rubens: induction by Asplanchna and effect on sexual reproduction. Hydrobiologia 844:9-20

Grebner W, Berglund EC, Berggren F, Eklund J, Harðadóttir S, Andersson MX, Selander E (2019) Induction of defensive traits in marine plankton-new copepodamide structures. Limnol Oceanogr 64:820-831

Jaturapruek R, Fontaneto D, Meksuwan P, Pholpunthin P, Maiphae S (2018) Planktonic and periphytic bdelloid rotifers from Thailand reveal a species assemblage with a combination of cosmopolitan and tropical species. Syst Biodivers 16:128-141

Kaczmarek Ł, Roszkowska M, Fontaneto D, Jezierska M, Pietrzak B, Wieczorek R, Poprawa I, Kosicki JZ, Karachitos A, Kmita H (2019) Staying young and fit? Ontogenetic and phylogenetic consequences of animal anhydrobiosis. J Zool 309:1-11

Lürling M, van Donk E (1997) Morphological changes in Scenedesmus induced by infochemicals released in situ from zooplankton grazers. Limnol Oceanogr 42:783-788
Nandini S, Zúñiga-Juárez FS, Sarma SSS (2014) Direct and indirect effects of invertebrate predators on population level responses of the rotifer Brachionus havanaensis (Rotifera). Int Rev Hydrobiol 99:107-116

Parigi A, Porter C, Cermak M, Pitchers WR, Dworkin I (2019) The behavioral repertoire of Drosophila melanogaster in the presence of two predator species that differ in hunting mode. PLoS ONE 14:e216860

Parsons MH, Apfelbach R, Banks PB, SparrowBlumstein EEDT (2018) Biologically meaningful scents: a framework for understanding predator-prey research across disciplines. Biol Rev 93:98-114

Pejler B, Bērziņš B (1993) On choice of substrate and habitat in bdelzoid rotifers. Hydrobiologia 255(256):333-338

Pietrzak B, Pijanowska J, Dawidowicz P (2017) The effect of temperature and kairomone on Daphnia escape ability: a simple bioassay. Hydrobiologia 798:15-23

Pijanowska J, Markowska M, Ruszczyńska A, Bulska E, Dawidowicz P, Ślusarczyk M, Biesaga M (2020) Kairomone-like activity of bile and bile components: a step towards revealing the chemical nature of fish kairomone. Sci Rep 10:7037

Pinheiro J, Bates D, DebRoy S, Sarkar D, R Core Team (2019) nlme: linear and nonlinear mixed effects models. R package version $3.1-141$

R Core Team (2019) R: A language and environment for statistical computing. R Foundation for Statistical Computing, Vienna, Austria. https://www.r-project.org/

Ricci CN (1987) Ecology of bdelloids: how to be successful. Hydrobiologia 147:117-127

Ricci C (2017) Bdelloid rotifers: 'sleeping beauties' and 'evolutionary scandals', but not only. Hydrobiologia 796:277-285

Ricci C, Melone G (2000) Key to the identification of the genera of bdelloid rotifers. Hydrobiologia 418:73-80

Riessen HP, Gilbert JJ (2019) Divergent developmental patterns of induced morphological defenses in rotifers and Daphnia: Ecological and evolutionary context. Limnol Oceanogr 64:541-557

Ślusarczyk M, Pinel-Alloul B, Pietrzak B (2019) Mechanisms facilitating dispersal of dormant eggs in a planktonic crustacean. In: Alekseev V, Pinel-Alloul B (eds) Dormancy in aquatic invertebrates. Theory, human use and modelling, Monographiae Biologicae. Springer, Cham, pp 137-161

Stephenson JF (2016) Keeping eyes peeled: guppies exposed to chemical alarm cue are more responsive to ambiguous visual cues. Behav Ecol Sociobiol 70:575-584

Therneau T (2020) A Package for Survival Analysis in R. R package version 3.1-12, https://CRAN.R-project.org/package=survival

Welch DM, Meselson M (2000) Evidence for the evolution of bdelloid rotifers without sexual reproduction or genetic exchange. Science 288:1211-1215

Wilson CG, Sherman PW (2013) Spatial and temporal escape from fungal parasitism in natural communities of anciently asexual bdelloid rotifers. Proc Roy Soc B 280:20131255

Publisher's Note Springer Nature remains neutral with regard to jurisdictional claims in published maps and institutional affiliations. 